\title{
Feminist Documentary Cinema as a Diffraction Apparatus for the Visualisation of Care Labour: The Spanish Collective Film Cuidado, resbala (2013)
}

\section{Orianna Calderón}

"GRACE: Gender and Cultures of Equality in Europe" Marie Curie Research Project

Institute for Women's Studies, University of Granada, Spain

orianna@correo.ugr.es

Instituto Universitario de Investigación de Estudios de las Mujeres y de Género

Universidad de Granada. Rector López Argüeta18071 Granada, Spain

This is a final peer-reviewed manuscript accepted for publication, which appears as:

Calderón, Orianna. "Feminist documentary cinema as a diffraction apparatus for the visualisation of care labour: the Spanish collective film Cuidado, resbala (2013)." Feminist Media Studies. 17.2 https://doi.org/10.1080/14680777.2017.1283750

Orianna Calderon is a PhD Candidate at the University of Granada and an Early Stage Researcher for GRACE "Gender and Cultures of Equality in Europe" - Horizon 2020, Marie Curie Research Project GRACE-led by Dr. Suzanne Clisby (Project P.I.) at the University of Hull. ESR 13: Visualising Gender Equality in Europe Through Art and Screen. Work Package 4 Textual and Artistic Cultures of Gender Equality. Principal Investigator Prof. Adelina Sánchez Espinosa. http://graceproject.eu

This work was supported by the European Union's Horizon 2020 research and innovation programme under the Marie Skłodowska-Curie grant agreement No. 675378 


\section{Feminist Documentary Cinema as a Diffraction Apparatus for the Visualisation of Care Labour: The Spanish Collective Film Cuidado, resbala (2013)}

This essay analyses the Spanish documentary film Cuidado, resbala (María Camacho Gómez, Montserrat Clos Fabuel, Mercedes Cordero Suárez, Vanessa Gómez Martínez, Carolina Suarez Rasmussen and Leonor Jiménez Moreno, 2013) as a diffraction apparatus that renders visible gendered inequalities surrounding care labour in the current socio-economic system. The title of Cuidado, resbala plays with the two meanings of the word "cuidado" in Spanish and can be translated as Caution/Care Slippery. It is directed by two psychologists, a pedagogue, a lawyer, a teacher and a filmmaker from two different associations based in Malaga, Spain: Circle of Women and The Inverted Gaze. Circle of Women was created in 1994 with the aim of promoting fair working conditions for women by means of participatory action research. The Inverted Gaze is a network of communication professionals whose work focuses on social issues; after Cuidado, resbala, they directed Boconas (Big Mouth Women, 2016) about Bolivian domestic workers, and they have carried out collaborative video workshops in Spanish high schools so as to raise awareness about global care chains.

Feminist economics proposes the metaphor of an iceberg to explain the current socio-economic system: a hierarchical organisation sustained by inequalities, in which the production and distribution processes of the markets occupy the visible part, while life development tasks, such as care labour, remain invisible (Orozco 2010, 136). These are differences and exclusions that matter (Barad 2007, 30). The invisibilization of care as an economic activity, traversed by the sexual division of labour, is materialized in the 
conditions under which it is generally carried out by women, without social or monetary recognition (Orozco 2010, 136).

This essay's hypothesis is that Cuidado, resbala can be analysed as a diffraction apparatus that renders visible the hidden part of the iceberg described by feminist economics. The concept of diffraction apparatus has been elaborated by Karen Barad to define material-discursive practices that make boundaries within phenomena so as to make them intelligible in specific ways. These practices "enact what matters and what is excluded from mattering" (Barad 2007, 148) in each intra-action with the world. Despite its complex definition, a diffraction apparatus can be as simple as a question, which places the focus on one aspect instead of another; or a camera, which necessarily frames only a portion of what stands in front of it. Therefore, to employ diffraction as the approach to analyse a documentary film, means paying attention to the importance of the form in which it produces and presents its contents.

Diffraction is a concept used in physics to describe a phenomenon characteristic of wave behaviour, i.e. how waves combine when they overlap, and their apparent bending and spreading "when they encounter an obstruction" (Barad 2007, 28). A diffractive methodology, thus, "provides a way of attending to entanglements in reading important insights and approaches through one another" (Barad 2007, 30). Donna Haraway and Barad propose it as an alternative to reflection: "both are optical phenomena, but whereas reflection is about mirroring and sameness, diffraction attends to patterns of difference" (Barad 2007, 29). Moreover, these patterns do not just map where differences appear, but "where the effects of difference appear" (Haraway 2004, $70)$.

Using Bill Nichols' typology of modes of representation in documentary cinema (2001), we can classify Cuidado, resbala as an observational-participatory documentary 
film, with a couple of expositive animated sequences, and a reflexive voice-over that opens and closes the film. It is thus composed of four different waves of narration: group conversations, everyday images and interviews with domestic workers; talking heads of experts; animations; and the narrator's voice-over sequences. Through a diffractive lens, we can visualize how these four waves overlap within the film editing, hence revealing diverse and apparently spread insights on the issue of care labour as entangled.

To read Cuidado, resbala as a diffraction apparatus also means to move from a focus on representationalism to performativity: the film isn't understood as a representation of the so-called real world out there, which is then mirrored by the camera, but as a practice in which human elements (e.g. the filmmakers) and nonhuman elements (e.g. the camera) intra-act with other human and non-human parts of the world. Instead of "reflecting on representations", diffraction focuses on "accounting for how practices matter" (Barad 2007, 90). Decisions such as who to film, what to leave out in the editing, and what to present within each narrative wave, are to be considered as material-discursive practices, which produce patterns of differences. And these patterns have effects within the materiality of the film in terms of how it is constructed, and how it "engages with bodies and with the matter of the world" (Olivieri $2012,10)$.

Depending on how the diffraction apparatus-film is constructed, the recorded and shown phenomena will "emerge in particular ways, and through particular cuts" (Sauzet 2015, 41). In documentary cinema, this can be translated into the framing and editing decisions: the cuts that the filmmakers enact "produce determinate boundaries and properties of 'entities' within phenomena" (Barad 2007, 148). In the case of Cuidado, resbala, the feminist ethos that informs most of these cuts re-enacts what 
matters in a socio-economic system from a feminist perspective: to begin with, care labour is placed at the centre, instead of being left at the hidden part of the iceberg.

Moreover, the editing places two narrative waves at the same level: the voices of the domestic workers and the voices of the academic experts interviewed for the film (the feminist economist Amaia Orozco, the ecofeminist anthropologist Yayo Herrero and the jurist Mercedes Cordero). In this way, the film-diffraction apparatus produces knowledge in a horizontal way that entangles insights from personal experience with those from academic backgrounds. This is further developed with an expositive animation, in which a female voice-over explains the intersections of gender, class and nationality in the global care chain: women from the global South that have migrated to the global North are being exploited as domestic workers, so that women from the socalled first countries can conciliate their professions with household chores. Neither men, nor industries, nor the State assume any responsibility for care labour. Some care services are privatised, but as a whole, this only aggravates inequalities.

The voice-over belongs to Carolina Suarez Rasmussen, one of the film directors, a member of the association Circle of Women, and a migrant from Argentina who worked as a domestic worker in Spain for three years. The film starts with her testimony about finding out that domestic labour doesn't have the same legal status as other jobs, and finishes with her account of how the personal conflicts she has faced are connected with that fact, and thus have a collective political dimension. This testimony is key for reading Cuidado, resbala as a research journey and what she is looking for is exactly what a diffractive reading focuses on, i.e. "how different differences get made" (Barad $2007,30)$ and the effects they provoke. Throughout the film, the viewer is encouraged to recognise the way in which care labour is rendered invisible, labelled as different 
from other jobs within the patriarchal and neoliberal socio-economic system, placing the responsibility for life care on individuals, mainly women, rather than on the State.

A common feature of the realist documentary films made by feminist women in the Seventies is the presence of women talking to the camera in first person as representatives of their own experience. In a similar vein, the filmmakers of Cuidado, resbala interview domestic workers that live in Spain but come, not only from this country, but also from regions as diverse as Nicaragua and Senegal. Most of these testimonies show how, once becoming aware of their unequal situations, they get organised to demand labour rights. Towards the end of the film this process is made explicit with the introduction of the collective Territorio Doméstico (Domestic Territory), creators of the motto: "Because without us, the world does not move."

A diffractive methodology does not take any boundaries for granted, "but rather investigates the material-discursive boundary-making practices that produce 'objects' and 'subjects' and other differences out of, and in terms of, a changing relationality" (Barad 2007, 93). Being developed as participatory action research, actively involving domestic workers both as individuals and collectives, Cuidado, resbala questions the boundaries between subjects and objects being filmed. And in a similar way to that in which second wave feminists employed realist documentary cinema as a militant tool, some of the domestic workers that appear in the film have used it in diverse forums, so as to raise awareness and empower people who experience similar situations. ${ }^{1}$

The connection that Barad makes between diffraction and scientific practices can be translatable to documentary film theory: "Objectivity, instead of being about offering an undistorted mirror image of the world, is about accountability to marks on

\footnotetext{
${ }^{1}$ For example, the collective Territorio Doméstico has organised projections and debates at the feminist space Eskalera Karakola in Madrid, with the explicit purpose of visibilising their demands, such as urging the Spanish government to sign The Convention 189 on Domestic Workers, which sets basic standards for care labour: https:/www.facebook.com/GrupoTurin/posts/521941261218006
} 
bodies, and responsibility to the entanglements of which we are a part" (in Dolphjin and Van der Tuin 2012, 52). Cuidado, resbala is a feminist documentary film that manages to do this in terms of care labour; not by reflecting un/equal "realities", but by responsibly intra-acting with specific parts of the world, diffracting them with the camera and the editing in ways that redefine multiple boundaries: those between academic knowledge, personal experiences and political activism; those between subjects and objects on both sides of the camera; and those between domestic work and other economic activities. By placing care labour at the centre of the discussion, it sets up a diffraction pattern of differences, with the effect of making visible the invisible entanglements that sustain the iceberg.

\section{References}

- Barad, Karen. 2007. Meeting the Universe Halfway: Quantum Physics and the Entanglement of Matter and Meaning. Durham and London: Duke University Press.

- Boconas. 2016. Film. Directed by Leonor Jiménez Moreno, Montse Clos Fabuel and Sofía Fernández Galván. Spain: ASPA (Asociación Andaluza por la Solidaridad y la Paz), Agencia Andaluza de Cooperación Internacional para el Desarrollo, Granada City Council and Malaga City Council.

- Cuidado, resbala. 2013. Film. Directed by María Camacho Gómez, Montserrat Clos Fabuel, Mercedes Cordero Suárez, Vanessa Gómez Martínez, Leonor Jiménez Moreno and Carolina Suarez Rasmussen. Spain: Asociación Círculo de Mujeres and La Mirada Invertida.

- Dolphjin Rick and Iris Van der Tuin. 2012. New Materialism: Interviews and Cartographies. Michigan: Open Humanities Press. 
- Haraway, Donna. 2004. "The Promises of Monsters: A Regenerative Politics for Inappropriate/d Others." In The Haraway Reader, 63-124. New York and London: Routledge.

- Nichols, Bill. 2001. Introduction to Documentary. Bloomington: Indiana University Press.

- Olivieri, Domitilla. 2012. Haunted by Reality. Toward a Feminist Study of Documentary Film: Indexicality, Vision and the Artifice. Utrecht: Universiteit Utrecht. PhD Thesis.

- Orozco Amaia. 2010. "Diagnóstico de la crisis y respuestas desde la economía feminista." Revista de Economía Crítica. 9: 131-144.

- Sauzet, Sofie. 2015. "Thinking Through Picturing”. In Peta Hinton and Pat Treusch eds. Teaching with Feminist Materialisms, 37-51. Utrecht: ATGENDER.

- Territorio Doméstico. 2013. "Por la ratificación convenio 189 OIT.” September. Accessed December 5, 2016. https://www.facebook.com/GrupoTurin/posts/521941261218006 